\title{
Q uality of Life and Its Relationship to Social Alienation of Drug Addicts
}

\section{Nemaa Nady Abd El-Samee (Ph.D.)}

Assistant Professor social work with individual and families- Helwan University, Cairo, Egypt 



\section{Abstract:}

This study aimed to determine the relationship between the quality of life and social alienation of drug addicts. It also aimed at Identify indicators for social workers roles with addicts for helping them to improve their quality of life as well to reduce their sense of social alienation. A purpose sample of (92) was selected. The study found that there is a statistically significant inverse relationship at the level of significance (0.01) between the quality of life and social alienation of drug addicts, the level of quality of life dimensions for drug addicts is low, and the level of the dimensions of social alienation for drug addicts is medium.

\section{Keywords:}

Quality of life, social alienation, drug addicts.

\section{Introduction:}

Addiction is one of the social phenomena that all developing countries and advanced societies suffer from, this phenomenon spreads among different classes and ages especially among adolescents and young adults. It characterized by poor health, poor social functioning, and loss of control over drug use (Jha \& Singh, 2020 , p.2). Where destructive behavior is also widely noted as a major social problem (Pienaar, et.,al, 2017, p.521).

Drug addiction consider a major issue and one of the main causes of health, psychological and social problems. The increasing trend of drug abuse, especially among young people, is of great concern to the family and society as a whole (Shakeri, et.,al, 2020, p.91).

According to the World Drug Report 2020, issued by the United Nations Office on Drugs and Crime (UNODC), about 269 million people used drugs worldwide during 2018 , which is $30 \%$ more than in 2009.

The Addiction Control and Treatment Fund stated in the comprehensive national survey $(2014,2015)$ that the rate of drug abuse in Egypt is about 10.4\%, and this percentage is double the rate that The global average in any country ranges between $4-5 \%$, and also revealed that $27 \%$ drug addicts are females, while $73 \%$ drug addicts are males.

There are a number of factors that contribute to drug addiction, among young people. The results of Abu Manjil study (2012) showed that among the factors associated with drug abuse were the exposure to harsh treatment by parents, parental neglect, escape from family 
problems, contact with a group of drug addicts, easy access to drugs, leisure and lack of places for activities and entertainment., The results of Al-Huwaish study (2017) showed that there are a variety of factors that push young people to resort to drug abuse, which vary among the individual, the family, misconceptions, or even the community itself. There are other causes such as poverty, complex social relationships, psychological stress due to family problems, easy access to drugs (Sujan, et al., 2021, p.3)

The drug addicts usually suffer from psychological problems, including anxiety disorders, antisocial personality, and mood disorders (Saatcioglu, Yapici \& Cakmak, 2008, p.83). Where their health deteriorates because of skipping meals, and sleeping late excessive or reduced sleep time, and less physical activity (Sujan, et al., 2021, p.3). Substance abuse can also increase the risk of liver disease, heart disease, and kidney disease. Lungs, especially infectious diseases such as hepatitis B or C and HIV/AIDS. (Jha \& Singh, 2020, p.2). Therefor it is clear the addict faces many stresses and problems which negatively affect his relationships and interactions with the surrounding systems, and thus his quality of life.

The quality of life is one of the important issues facing contemporary societies. There is so countries are striving towards enhancing the citizen's quality of life (Hindi, 2017, p. 244).As Stevanovic, et. al (2015) noted that There is an inverse relationship between alcohol/drug use and quality of life among adolescents, the sample included 2393 male, where adolescents low socioeconomic status suffered from with greater decreases in quality of life levels.

In general, the quality of life for addicts is usually lower (Cerne et al., 2013, p.2). Where, Hoseinifar et al. (2011) compared the quality of life between addicts and non-addicts. The results of the study concluded that there are differences between the two groups in terms of quality of life and its sub-scales, where the quality of life of addicts was lower than that of non-addicts. Also study of Muller, Skurtveit \& Clausen (2016) showed that $(75 \%)$ of drug users indicated that the quality of life is "weak" or "bad," where depression has shown a strong association with poor quality of life. Moreover, lack of physical activity among drug users has been associated with very poor quality of life, and rating an individual's weight as too low was associated with poor quality of life.

Abdel-Samad (2019) identified the level of quality of life among a sample of drug-addicted youth, and its results showed a decrease in 
the quality of life of drug-addicted youth, also reached that there are statistical significant differences between drug addicts on the quality of life scale, according to the educational variable in favor of secondary education.

An assessment of quality of life is especially relevant with drug users, since substance abuse often has a negative impact on many areas of life, such as social relationships, work, personal safety, and physical and psychological health (Abrahamsson, Berglund \& Anders, 2015, p.271). Hallit, et. al. (2019) determined the factors associated with the quality of physical and mental life in a sample of addicted patients, and the results showed that the abuse of narcotic substances would lead to a deterioration in physical health such as physical pain, anger, and impaired social functioning and decreased of quality of life among addicts.

The symptoms of anxiety and depression associated with addiction lead to an increase in the severity of problems in addicts, which has a negative impact on their quality of life. The study of Saatcioglu, et al (2008) examined the nature of the relationship between quality of life and severity of depression and anxiety for addicts, and investigated whether quality of life differs between addicted individuals with and without depression and anxiety. The results of the study found that the quality of life in the areas of physical, psychological and environmental health differed significantly between groups of patients, with the exception of social relations. The quality of life was lower in patients with depression and higher in addicted patients with less anxiety and depression. This is consistent with the results of the study of Marcon, Rubira, Espinosa \& Barbosa (2013), Armstrong, et al., (2013), in the presence of a strong negative relationship between the quality of life and depression, anxiety and suicidal ideation for drug addicts.

The results of previous studies also showed that drug addicts have different psychological, physical, social and emotional needs than healthy individuals; behavioral changes resulting from drug abuse, as well as problems in relationships with the family, friends, etc. that all affect the quality of life. (Heydarpour, Jalali, Baghaei \& Salari, 2020, p.2).Suleiman (2015) study revealed that the quality of life is clearly disturbed for the dependents, compared to the nondependent. The study also concluded that the increase in the duration of use leads to a deterioration in the Quality of life. There is an inverse relationship between quality of life and turbulence in general, 
especially regarding the sub-domains of quality of life that contribute to predicting dependence, economic status and social relations had the most prominent role in predicting dependence.

The quality of life of drug addicts affected by some demographic variables. Miqdadi (2019) study revealed that there are no statistically significant differences due to the effect of age, educational level, economic status, in all areas of the quality of life of drug addicts. However, the findings indicated the presence of statistically significant differences due to the effect of social status only in physical and mental health. The study also indicated the absence of statistically significant differences due to the effect of social status on social and environmental relations. The study concluded that there were statistically significant differences between single people on the one hand and both married and divorced on the other hand, and the differences came in favor of both married and divorced in physical health. , There were also, statistically significant differences among single, divorced and widowed, and the differences were in favor of the divorced in mental health, and in the quality of life scale as a whole.

The quality of life may affected the addict adjustment with himself and with the surrounding social environment which may lead to a sense of social alienation.

Feelings of social alienation among adolescents and young adults can lead to behaviors such as violence, vandalism, absenteeism, deviant behavior, drug abuse, and alcohol abuse (Safipour, Tessma, Higginbottom \& Emami, 2010, p.517).

Alienation results of social isolation and meaninglessness is one of the main factors responsible for drug abuse (Ahmed, 2017, p. 15). Since addiction affects over time passively and the person lose Social bonds, social obligations, and acts secretly to obtain or abuse the substance and gets isolated from his family and friends (Nina, 2021, p.p1-3).

In this regard Horman's (2009) concluded that the feeling of alienation is directly related to drug abuse, and also increased isolation was associated with increased drug abuse. Kabqoub \& Saidi (2015) also concluded that alienation has a role in adolescent drug abuse. This is because social isolation, weak religious, and dysfunctional relationships lead adolescents to introversion and drug abuse.

Al-Saud \& Abu Romi (2019) showed that there are statistically significant differences in the level of social alienation between addicts 
and non-addicts in favor of addicts. The study did not show statistically significant differences in the level of social alienation among Addicts attributed to the variable social status. With regard to the age variable, there were statistically significant differences in the level of social alienation among addicts in favor of the older age groups. The results did not show any statistically significant differences in the degree of social alienation among addicts due to the educational level variable. This is consistent with the findings of the study of Al Saud \& Saud (2006) that drug addicts have a higher degree of alienation compared to non-addicts; and drug addicts are less assertive than non-addicts.

From the previous revue it is clear that most of the problems of the addict's system lie in the presence of a defect in the patterns of his sub-personality that pushes him to deviate as a natural reaction to the negative inputs of the system. Based on the previous introduced, and in light of the findings of previous studies it is clear that drug addicts suffer from many social, psychological, economic family stresses and problems or environmental problems which lead to low quality of life for addicts In addition, social alienation, including the feeling of social isolation and meaninglessness. As one of the main factors responsible for using drugs, and increase in the level of social alienation among drug addicts.

The addict is seen as a social system consisting of a group of sub-systems represented in the (physical-psychological-mental-socialbehavioral) and these patterns are in a state of interaction and mutual influence. Social alienation and a reduced quality of life are a result of the negative effects of addiction to these systems.

So the problem of the study is determined in the following question: What is the nature of the relation between quality of life and social alienation for drug addicts?

\section{Study Objectives:}

1) Determine the nature of the relationship between the quality of life and social alienation for drug addicts, and this is achieved through: addicts.

A - Determine the level of quality of life dimensions for drug addicts.

B - Determine the level of social alienation dimensions for drug

2) Identify indicators for social workers roles with addicts for helping them to improve their quality of life as well to reduce their sense of social alienation. 


\section{Study Concepts:}

\section{1- Quality of life:}

The World Health Organization defines quality of life as "the individual's awareness of his or her situation in life in the cultural context and value system associated with goals, expectations and standards in their lives" and therefore it is a broad concept that includes individuals' physical health, psychological state, level of independence, social relationships, personal beliefs and their relationship to important aspects in the environment in which it lives. (Hallit, et. al., 2019, p.379).

The Theoretical definition of quality of life: satisfying the basic needs of the addict, improving physical and psychological health, and social relations, and linking them to his own goals and expectations to help him live a good life that reflects his life satisfaction.

The concept of quality of life is measured procedurally through the addict degree obtained on the quality of life scale and its dimensions as follows:
1) Physical health.
3) Social relations
2) Psychological Health.
4) The environment.

\section{2- Social alienation:}

Social alienation is defined as a form of social exclusion or society marginalization in which minorities experience that and social hardships. It is "a condition in social relations, reflected in a low degree of integration or shared values and a high degree of distance or isolation between individuals." (Matusitz, 2020, p.103).

The Theoretical definition of social alienation: the isolation of the addict from society and his look of intimate social relations and distance from others, and that his life is meaningless, useless and live without a specific purpose.

Social alienation is measure procedurally by the addict degree obtained on the social alienation scale and its dimensions as follows:

1) Social isolation: It means "the individual's feeling of being separated from the members of the same community".

2) The meaningless: It means "the individual's feeling that there is no meaning in life that his activities and roles have no meaning, and that there are no goals worthy to bears the difficulties of life." 


\section{Theoretical Guidelines of the Research: System theory}

The System theory was introduced by Von Bertalanffy (1968) as a general theory of the organization of parts into a whole (Barker, 2007, p.29). which rejected linear, cause and effect models, proposing instead that change results from interactions between the different parts of an organism and he sought to understand how these different parts interact to purposely create a whole (Teater, 2014, p.17).

System theory identify the central importance of seeing the person in their context, and understanding that this is not a static picture. The individual is always interacting with wider systems/their environment. These interactions are reciprocal so that a change in one aspect will always produce a change somewhere else in the system (Deacon\& Macdonald, 2017, p.92).The addict is seen as a social system consisting of a group of sub-systems represented in (physicalpsychological-mental-social-behavioral) and these systems are in a state of interaction and mutual influence. In the case of an individual's addiction, all of these systems are affected and have an impact on the physical health dimension, the psychological dimension, social relations, and finally the environment, which leads to low his quality of life and also increases the feeling of social alienation. The behavior of an addict from the point of view of system theory can be understood as an outcome or a product of the social situation as a whole in which he finds himself.

\section{Methodology:}

This study belongs to the pattern of descriptive studies, to determine the relationship between two variables, namely: quality of life and social alienation of drug addicts. This study relied on the social survey method, using the purposive sampling method.

\section{Study hypotheses:}

1- There is a statistically significant inverse relationship between the quality of life in its various dimensions (the physical health dimension, the psychological dimension, the social relations dimension, and the environment dimension) and the social alienation of drug addicts (the social isolation and the meaninglessness).

2-There is a statistically significant correlation between some demographic variables (age, marital status, number of children, educational status, occupational status, average monthly income, duration of use, number of relapses) and quality of life for drug addicts. 


\begin{tabular}{|lr||}
\hline Egyptian Journal of Social Work (EJSW) & http://ejsw.journals.ekb.eg \\
ISSN: $2356-9204$ & Vol 13, Issue 1, January 2022 \\
\hline
\end{tabular}

3-There is a statistically significant correlation between some demographic variables (age, marital status, number of children, educational status, occupational status, average monthly income, duration of use, number of relapses) and social alienation for addicts.

Sample: The sample frame consists of (255) drug addicts who received treatment at Al-Khanka Psychiatric Hospital during the period between $8 / 6 / 2021$ - 4/8/2021, the study sample consisted of (92) addicts who were selected by the purposive sample method according to the following conditions:

1) Agreeing to cooperate with the researcher to obtain the data.

2) Proficiency in reading and writing.

3) Age ranges from 25 to 35 years.

4) They do not have a double diagnosis of any disorders other than addiction.

The Sample unit characteristics are shown in Table (1) as follows:

Table (1) Description of the characteristics of the study sample

\begin{tabular}{|c|c|c|c|c|c|c|c|}
\hline Variables & $\begin{array}{c}\text { Variable } \\
\text { classes classes }\end{array}$ & number & $\%$ & Variables & $\begin{array}{l}\text { Variable } \\
\text { classes }\end{array}$ & number & $\%$ \\
\hline \multirow{5}{*}{ age } & $\begin{array}{c}\text { From } 25 \text { years } \\
\text { to less than } 30 \\
\text { years. }\end{array}$ & 44 & 47.8 & \multirow{5}{*}{$\begin{array}{c}\text { professional } \\
\text { status }\end{array}$} & work & 64 & 69.6 \\
\hline & $\begin{array}{c}\text { From } 30 \text { years } \\
\text { old to less than } \\
35 \text { years old. }\end{array}$ & 48 & 52.2 & & $\begin{array}{c}\text { not } \\
\text { work }\end{array}$ & 25 & 27.2 \\
\hline & Total & 92 & 100 & & \multirow{2}{*}{$\begin{array}{c}\text { student } \\
\text { Total }\end{array}$} & \multirow{2}{*}{$\begin{array}{c}3 \\
92 \\
\end{array}$} & $\begin{array}{l}3.3 \\
92 \\
\end{array}$ \\
\hline & Mean & \multicolumn{2}{|c|}{30.10} & & & & \multirow{2}{*}{100} \\
\hline & S. D & \multicolumn{2}{|c|}{3.03} & & Total & 92 & \\
\hline \multirow{5}{*}{$\begin{array}{l}\text { Social } \\
\text { status }\end{array}$} & single & 38 & 41.3 & \multirow{5}{*}{$\begin{array}{l}\text { average } \\
\text { monthly } \\
\text { income }\end{array}$} & \multirow{3}{*}{ mean } & \multirow{3}{*}{\multicolumn{2}{|c|}{1934.8}} \\
\hline & Married & 29 & 31.5 & & & & \\
\hline & absolute & 23 & 25.0 & & & & \\
\hline & Widower & 2 & 2.2 & & S D D & 1412 & \\
\hline & Total & 92 & 100 & & S. & 1412 & \\
\hline & No children & 41 & 44.6 & & & & \\
\hline & One & 13 & 14.1 & & mean & 7.11 & \\
\hline number of & Two & 23 & 25.0 & duration of & & & \\
\hline children & three or more & 15 & 16.3 & use & & & \\
\hline & Total & 92 & 100 & & S. & 5.1 & \\
\hline & Mean & 2. & & & & & \\
\hline
\end{tabular}




\begin{tabular}{|c|c|c|c|c|c|c|c|}
\hline \multicolumn{4}{|c|}{$\begin{array}{l}\text { Egyptian Journal of Social Work (EJSW) } \\
\text { ISSN: 2356-9204 }\end{array}$} & \multicolumn{4}{|c|}{$\begin{array}{r}\text { http://ejsw.journals.ekb.eg } \\
\text { Vol 13, Issue 1, January } 2022\end{array}$} \\
\hline Variables & $\begin{array}{c}\text { Variable } \\
\text { classes classes }\end{array}$ & number & $\%$ & Variables & $\begin{array}{l}\text { Variable } \\
\text { classes }\end{array}$ & number & $\%$ \\
\hline \multirow{4}{*}{$\begin{array}{l}\text { Educational } \\
\text { Status }\end{array}$} & $\begin{array}{c}\text { Reads and } \\
\text { writes }\end{array}$ & 31 & 33.7 & \multirow{4}{*}{$\begin{array}{l}\text { The number } \\
\text { of relapses }\end{array}$} & \multirow{2}{*}{ mean } & \multirow{2}{*}{\multicolumn{2}{|c|}{3.01}} \\
\hline & $\begin{array}{l}\text { intermediate } \\
\text { qualification }\end{array}$ & 44 & 47.8 & & & & \\
\hline & High qualified. & 17 & 18.5 & & \multirow{2}{*}{ S. D } & \multirow{2}{*}{\multicolumn{2}{|c|}{2.54}} \\
\hline & Total & 92 & 100 & & & & \\
\hline
\end{tabular}

- The table above shows that the age average of the study sample is (30.10) years with a standard deviation of (3.03) and this reflects that the study sample is young people. This group is one of the most targeted groups for drug addiction. Substance abuse is higher among the youth group (Shakeri, et.,al, 2020, p.91).

- It also became clear that the highest percentage of the study sample is from the category (single) at $41.3 \%$. This may be due to the the fact that the drug addict prefers to be single, and no hence bear the responsible or expenses of marriage or form of a family. To live for himself and spend his money on the narcotic substance. Addiction becomes a priority in his life.

- It was also found that the average number of children is (2.13). This may be because the largest proportion of the study sample is from the category of singles.

- It was also clear that for the educational level, the largest percentage $(47.8 \%)$ hold an intermediate qualification. This means that the educational level cannot be a protective shield.

- The results of the study sample showed that the highest percentage (69.6\%) are working so they can pay for drugs and may belief that drugs may increase their ability to work and achieve. or drugs have a positive effect in improving their mood and hence, improving their quality of life and may forget life's problems and stresses.

- The results of the study sample showed that the average monthly income is (1934.8) with a standard deviation (1412.6). This may be because the income is available to them to buy the drug. However, with time the addicts lose their sources of income.

- It is clear from the previous table that the average duration of use is (7.10). This is because the study sample may started by smoking cigarettes, at their early adolescence, and then went to drug addiction. 
- As it became clear from the previous table that the average number of relapse times (3.01). This may be due to the ineffectiveness of treatment without changing the social conditions surrounding them.

Tools: The first scale: The scale of Quality of Life "The Brief Image" prepared by (WHO, 1996) Arabization (Ahmed, B. I., 2013).

Description of the scale: The scale consists of 26 statements, two of which are about quality of life and public health, in general; 24 items distributed over four sub-dimensions of the scale.

Table (2) shows the statements of the quality of life scale on four dimensions

\begin{tabular}{||c||c||c|}
\hline Dimensions & Phrase numbers & Total \\
\hline \hline physical health & $\mathbf{3 , 4 , 1 0 , 1 5 , 1 6 , 1 7 , 1 8}$ & $\mathbf{7}$ \\
\hline \hline Psychological health & $\mathbf{5 , 6 , 7 , 1 1 , 1 9 , 2 6}$ & 6 \\
\hline \hline Social relations & $\mathbf{2 0 , 2 1 , 2 2 ,}$ & 3 \\
\hline \hline The environment & $\mathbf{8 , 9 , 1 2 , 1 3 , 1 4 , 2 3 , 2 4 , 2 5}$ & $\mathbf{8}$ \\
\hline \hline Total & $\mathbf{2 4}$ & $\mathbf{2 4}$ \\
\hline
\end{tabular}

*Phrases (1 and 2) express the quality of life as a whole and do not follow any dimension.

Scale correction and total score: The scale items are answered according to a listed scale, with scores ranging from five to one. In the case of a positive answer, a high score indicates quality of life. These scores are reflected in the case of negative answers.

The researcher re-performed the stability operations of the scale to verify its suitability for the current research. The tool was applied to a sample consisting of (10) addicts not from the basic research sample but it has the same properties. Alpha (.830), which is a high coefficient, and the split-half method using the Spearman-Brown coefficient and its value (.947). This indicates the validity of the scale for application.

Quality of Life Scale Correction Method: To judge the level of quality of life, the beginning and end of the five-scale categories are as follows: very high (five), highly applicable (four), moderately applicable (three), apply low (two), apply very low (1 degree).the 


\section{length of the cells as follows:}

Table (3) Levels of Arithmetic Averages

\begin{tabular}{||c||c||}
\hline $\begin{array}{r}\text { If the mean value of the expression or dimension ranges from 1 } \\
\text { to less than } 1.8\end{array}$ & very low level \\
\hline \hline $\begin{array}{r}\text { If the mean value of the expression or dimension ranges from } \\
1.8 \text { to less than } 2.6\end{array}$ & low level \\
2.6 to less than 3.4 & average level \\
\hline \hline If the mean value of the expression or dimension ranges from & high level \\
\hline \hline If the mean value of the expression or dimension ranges from & very high level \\
\hline \hline $\begin{array}{r}\text { If the mean value of the expression or dimension ranges between } \\
4.2 \text { to } 5\end{array}$ & \\
\hline
\end{tabular}

The second scale: The Social Alienation Scale, prepared by / Abdel Wahab, A. A., 2016

Scale description: The scale consists of (28) items that describe the feeling of social alienation, and is divided into two subdimensions: Social isolation (14) items and item numbers are: 1-3-57-9-11-13-15-17-19 -21-23-25-27, and after the meaningless (14) an item and its numbers 2-4-6-8-10-12-14-16-18-20-22-24-26-28.

Scale correction: The items of the scale are answered by choosing one of the following options: "always," sometimes, "rarely," never." The scores are 3,2,1, and zero, where " 3 " indicates a strong sense of social alienation for the individual. Zero refers to a strong awareness that there is no social alienation. The higher the degree on the high the perception of social alienation is. Then, the degree ranges between zero and (84).The degree reflects in the case of negative responses for the statements 7-17-27, the scores are zero, 1, 2, and 3.

\section{follows:}

The researcher has re-conducted the validity and reliability as

Scale validity: Internal consistency validity The researcher applied the tool to a sample of (10) addicts not from the basic research sample and it has the same characteristics, and the correlation coefficients were calculated between the total scores of each dimension of the scale and the total score of the scale. This is shown as follows: 
Table (4) shows the internal consistency between the dimensions of the social alienation scale and the degree of the scale as a whole $(\mathrm{N}=10)$

\begin{tabular}{||c||c||c|}
\hline Dimensions & Correlation coefficient & Level of significance \\
\hline \hline Social isolation & $\mathbf{9 5 0}$ & $* *$ \\
\hline \hline meaningless & $\mathbf{9 6 0}$ & $* *$ \\
\hline$* *$ significant at $(0.01)$ & & $*$ significant at $(0.05)$ \\
\hline
\end{tabular}

The table above shows that all correlation coefficients are significant, which indicates the validity of the scale for use in what it was designed for.

Scale reliability: reliability was calculated in two ways, including: Cronbach's alpha method, where the reliability coefficient was alpha (.919), which is a high coefficient, and the split-half method using Spearman-Brown's coefficient and its value (.825), which indicates the validity of the scale for application.

Correction method for the social alienation scale: To judge the level of social alienation, the beginning and end of the quadrant scale categories are: very often (three degrees), frequently (two degrees), sometimes (1 degree), never (zero). The length of the cells as follows: Table (5) Levels of Arithmetic Averages

\begin{tabular}{|c|c|}
\hline $\begin{array}{c}\text { If the mean value of the expression or dimension ranges from } 0 \\
\text { to less than } 0.6\end{array}$ & $\begin{array}{c}\text { very low } \\
\text { level }\end{array}$ \\
\hline $\begin{array}{l}\text { If the mean value of the expression or dimension ranges from } \\
0.6 \text { to less than } 1.2\end{array}$ & low level \\
\hline $\begin{array}{l}\text { If the mean value of the expression or dimension ranges from } \\
1.2 \text { to less than } 1.8 \\
\end{array}$ & average level \\
\hline $\begin{array}{l}\text { If the mean value of the expression or dimension ranges from } \\
1.8 \text { to less than } 2.4 \\
\end{array}$ & high level \\
\hline $\begin{array}{c}\text { If the mean value of the expression or dimension ranges } \\
\text { between } 2.4 \text { to3 }\end{array}$ & $\begin{array}{c}\text { very high } \\
\text { level }\end{array}$ \\
\hline
\end{tabular}

Study results: The first axis: the level of quality of life dimensions for drug addicts.

Table (6) Shows the level of quality of life dimensions for drug addicts $(\mathrm{N}=92)$

\begin{tabular}{||c||c||c||c||c||}
\hline Dimensions & mean & S.D & the level & ranking \\
\hline \hline physical health & $\mathbf{2 . 5 8}$ & $\mathbf{0 . 5 8}$ & Low & 1 \\
\hline \hline Psychological health & $\mathbf{2 . 5 2}$ & $\mathbf{0 . 6 5}$ & Low & 2 \\
\hline \hline Social relations & 2.50 & $\mathbf{0 . 8 0}$ & Low & $\mathbf{3}$ \\
\hline \hline The environment & 2.27 & $\mathbf{0 . 6 3}$ & Low & 4 \\
\hline $\begin{array}{c}\text { dimensions of quality } \\
\text { of life as a whole }\end{array}$ & 2.45 & $\mathbf{0 . 0 5}$ & \multicolumn{2}{|c||}{ low level } \\
\hline \hline
\end{tabular}


The table above shows that the level of quality of life dimensions for drug addicts is low, with an arithmetic mean of (2.45).

The second axis: the level of dimensions of social alienation for drug addicts:

Table (7) shows the level of social alienation dimensions for drug addicts

\begin{tabular}{||c||c||c||c||c||}
\hline Dimensions & Mean & S.D & the level & ranking \\
\hline \hline Social isolation & 1.62 & 0.37 & medium & 1 \\
\hline \hline Meaningless & 1.29 & 0.29 & medium & 2 \\
\hline \hline $\begin{array}{c}\text { The dimensions of social } \\
\text { alienation as a whole }\end{array}$ & 1.45 & 0.28 & medium level \\
\hline
\end{tabular}

The table above shows that the level of the dimensions of social alienation for drug addicts is medium, where the arithmetic mean is (1.45).

The study hypotheses results: The first hypothesis: There are a statistically significant inverse relationship between the quality of life and the social alienation of drug addicts (the dimension of social isolation and the dimension of meaninglessness).

Table (8) shows the relationship between quality of life and social alienation for drug addicts

\begin{tabular}{||c||c||c||c||c||c||}
\hline Dimensions & $\begin{array}{c}\text { physical } \\
\text { health }\end{array}$ & $\begin{array}{c}\text { Psychological } \\
\text { health }\end{array}$ & $\begin{array}{c}\text { Social } \\
\text { relations }\end{array}$ & $\begin{array}{c}\text { The } \\
\text { environment }\end{array}$ & $\begin{array}{c}\text { dimensions } \\
\text { of quality } \\
\text { of life as a } \\
\text { whole }\end{array}$ \\
\hline \hline $\begin{array}{c}\text { Social } \\
\text { isolation }\end{array}$ & $* * \mathbf{0 . 3 9 3}$ & $\mathbf{0 . 1 7 5}$ & $* \mathbf{0 . 2 1 4}$ & $\mathbf{0 . 1 4 1}$ & $* \mathbf{0 . 2 6 4}$ \\
\hline Meaningless & $* * \mathbf{0 . 9 2 2}$ & $* * \mathbf{0 . 5 6 4}$ & $* * \mathbf{0 . 4 9 7}$ & $* * \mathbf{0 . 6 5 5}$ & $* * \mathbf{0 . 8 1 2}$ \\
\hline $\begin{array}{c}\text { The } \\
\text { dimensions } \\
\text { of social } \\
\text { alienation } \\
\text { as a whole }\end{array}$ & $* * \mathbf{0 . 7 8 5}$ & $* \mathbf{0 . 4 1 1}$ & $* * \mathbf{0 . 4 0 2}$ & $* * \mathbf{0 . 4 3 5}$ & $* * \mathbf{0 . 6 0 0}$ \\
\hline
\end{tabular}

**significant at $(0.01)$

*significant at $(0.05)$

The table above shows that there is a statistically significant inverse relationship at a level of (0.01) between the dimensions of quality of life as a whole and social alienation, among drug addicts. The level of the quality of life decreased as the feeling of social alienation increased, for drug addicts. Although there is a statistically significant inverse relationship between the dimensions of the quality 
of life as a whole and social alienation as a whole, among drug addicts, it is not significant among some of the sub-dimensions. The study concluded in its results that there is no relationship between the dimension of social isolation and both dimensions of mental health and environment, thus proving validity the first hypothesis of research.

The second hypothesis: There is a statistically significant correlation between some demographic variables (age, marital status, number of children, educational status, occupational status, average monthly income, duration of use, number of relapses) and quality of life for drug addicts.

Table (9): The relationship between some demographic variables and quality of life for drug addicts.

$(\mathrm{N}=92)$

\begin{tabular}{|c|c|c|c|}
\hline \multirow{2}{*}{$\begin{array}{c}\text { Demographic } \\
\text { variables }\end{array}$} & \multicolumn{3}{|c|}{ The level of Quality of life for drug addicts } \\
\hline & $\begin{array}{c}\text { The parameter } \\
\text { used }\end{array}$ & $\begin{array}{c}\text { Its value and } \\
\text { meaning } \\
\end{array}$ & \\
\hline Age & Pearson & .054 & \\
\hline Social status & Ca2 & 1.141 & $(\mathrm{D} . \mathrm{F}=126)$ \\
\hline number of children & Pearson & .142 & \\
\hline Educational Status & Ca2 & 93.64 & (D.F =84) \\
\hline professional status & Ca2 & 62.415 & $(\mathbf{D}$ (D.F =84) \\
\hline $\begin{array}{l}\text { average monthly } \\
\text { income }\end{array}$ & Pearson & $* * .271$ & \\
\hline duration of use & Pearson & -.100 & \\
\hline $\begin{array}{c}\text { The number of } \\
\text { relapses }\end{array}$ & $\overline{\text { Pearson }}$ & -.105 & \\
\hline
\end{tabular}

The table above shows that there is a statistically significant relationship between one of the demographic variables (average monthly income) and the quality of life for drug addicts. As for the other variables (age, marital status, number of children, educational status, occupational status, duration of use, number of relapses), the quality of life of drug addicts does not differ accordingly, thus rejecting the second hypothesis of the study.

The third hypothesis: There is a statistically significant correlation between some demographic variables (age, marital status, number of children, educational status, occupational status, average monthly income, duration of use, number of relapses) and social alienation for drug addicts. 
Table (10) the relationship between some demographic variables and social alienation

$(\mathrm{N}=92)$

\begin{tabular}{|c|c|c|c|}
\hline \multirow[t]{2}{*}{ demographic variables } & \multicolumn{3}{|c|}{ The level of social alienation of drug addicts } \\
\hline & $\begin{array}{c}\text { The parameter } \\
\text { used }\end{array}$ & $\begin{array}{c}\text { Its value and } \\
\text { meaning }\end{array}$ & \\
\hline Age & Pearson & .001 & \\
\hline Social status & Ca2 & 87.70 & $(\mathrm{D} . \mathrm{F}=90)$ \\
\hline number of children & Pearson & .053 & \\
\hline Educational Status & Ca2 & 48.73 & $(\mathrm{D} . \mathrm{F}=60)$ \\
\hline professional status & Ca2 & 50.00 & $(\mathrm{D} . \mathrm{F}=60)$ \\
\hline $\begin{array}{c}\text { average monthly } \\
\text { income }\end{array}$ & Pearson & 2.056 & \\
\hline duration of use & Pearson & -.103 & \\
\hline $\begin{array}{c}\text { The number of } \\
\text { relapses }\end{array}$ & Pearson & .077 & \\
\hline
\end{tabular}

**significant at $(0.01)$

*significant at $(0.05)$

The table above shows that there is no statistically significant relationship between some demographic variables and social alienation for drug addicts. This means that social alienation for drug addicts does not differ according to different demographic variables, thus rejecting the third hypothesis of the study.

\section{Discussion:}

The current study found that low level of the quality of life dimensions for drug addicts. This is consistent with the findings of Hoseinifar et al. (2011), Muller et al. (2016), Abdel Samad (2019), regarding the decrease in the quality of life of drug addicts. The findings are also consistent with Hallit, et. al. (2019), who found that substance abuse may lead to deterioration in physical health such as physical pain, and impairment of social functioning. The current study agrees with what was stated in the theoretical framework that the quality of life for addicts is usually lower (Cerne et al., 2013, p.2) and consistent with (Heydarpour,et al., 2020, p.2). According to the systems theory, the addict is a social system that consists of a group of sub-systems represented in the (physical-psychological-mental-socialbehavioral) and these systems are in a state of interaction and mutual influence. The psychological, social relations and the environment interact, which leads to decrease in his quality of life.

The study also concluded that the level of the dimensions of social alienation for drug addicts is medium. This is consistent with the results of the study of Al Saud\& Saud (2006), whose results found that drug addicts have a higher degree of alienation compared to non- 
addicts. Horman (2009) concluded that the feeling of alienation is directly related to drug abuse, and increased isolation was associated with increased drug abuse. This is also in agreement with the findings of Al-Saud \& Abu Romiy (2019), in the presence of statistically significant differences in the level of social alienation between addicts and non-addicts in favor of addicts. It also agrees with what was stated in the theoretical framework: that the abuser or addict feels incapable making any decisions, and that his life goes on without a clear goal or purpose. The addict also feels that there is no meaning in what he is doing and eventually loses the purpose of his existence and his life becomes meaningless. As a result, the addict suffers from feeling of loneliness and self-contempt, and then a feeling of alienation (Ahmed, 2017, p. 81). According to systems theory, addiction affects the relationships and interactions of the individual, which makes him feel socially alienated due to the negative effects of addiction, and therefore he needs to deal with these systems until he reaches a state of social adjustment.

The current study found that there is a statistically significant inverse relationship at a level of (0.01) between the dimensions of quality of life as a whole and social alienation as a whole among drug addicts where the level of the quality of life decreased as the feeling of social alienation increased for drug addicts but there is no significant among some of the sub-dimensions, as the study concluded that there is no relationship between the dimension of social isolation and both dimensions of mental health and environment. This is consistent with the results of Hoseinifar et al. (2011). Abdel-Samad (2019) showed a decrease in the quality of life of drug addicts, and this is also consistent with the results of Muller et al. (2016), which concluded that $(75 \%)$ of drug users indicated that their quality of life was "poor" or "very poor". Drug use leads to a deterioration in the physical strength and the quality of life of addicts. It also agrees with the findings of Saatcioglu, et al (2008), proving the quality of life in the areas of physical, psychological and environmental health was significantly reduced among groups of addicts, excluding social relationships. It also agrees with the results of the study of Marcon, et al (2012), Armstrong, et al., (2013), in the existence of a strong negative relationship between the quality of life and depression, anxiety and suicidal ideation for drug addicts. It also agrees with what was stated in the theoretical framework that drug addicts suffer from undesirable behavioral changes, as well as social problems affect their 
quality of life (Heydarpour, et al., 2020, p.2). And this is also consistent with what was indicated by the results of the study of Al Saud \& Saud (2006), Horman (2009), and Al-Saud \& Abu Romi (2019), who noted the increase in the level of social alienation among drug addicts. According to systems theory, the addict is a social system that consists of a group of sub-systems (physicalpsychological-mental-social-behavioral). The researcher believes that the addict's pattern will undoubtedly affect his relationships, interactions and connections with other patterns surrounding him, leading to become a closed system that cannot exchange ideas, information and benefits with the surrounding structures, due to the feeling of social alienation imposed by his addiction.

The study also concluded that there are a statistically significant relationship between one of the demographic variables (average monthly income) and the quality of life for drug addicts, this is consistent with the results of Solomon's study (2015) that is, and the field of economic status had the most prominent role in predicting dependence. This differs from the results of Miqdadi's study (2019), which concluded that there are no statistically significant differences due to the impact of economic status, in all areas of quality of life. As for the rest the variables the quality of life of drug addicts does not differ accordingly. This is consistent with the results of Soliman's study (2015), whose results showed that there are no statistically significant differences attributable to the effect of social status on social and environmental relations. Additionally, Miqdadi (2019) concluded that there were no statistically significant differences due to the effect of age, educational level, in all areas of the quality of life. This is inconsistent with the results of Suleiman's study (2015), which found that increasing the duration of substance abuse leads to a deterioration in the quality of life. Moreover, Miqdadi (2019) found statistically significant differences due to the effect of social status only in physical health. The differences were in favor of both married and divorced individuals, in physical health. There were statistically significant differences between single, divorced and widowed mental health, and in the quality of life scale, as a whole. The results of the current study also differed from the results of the study of AbdelSamad (2019), which concluded that there were statistically significant differences among the study sample in the quality of life, according to the educational level variable, in favor of secondary education. 
The study also concluded that there is no statistically significant relationship between some demographic variables and social alienation for drug addicts, and this is consistent with the results of the Al-Saud \& Abu Romi (2019). They concluded that there were no statistically significant differences in the level of social alienation among addicts, due to the variable of social status as well as the variable of educational level. The results of their study differed from the current study in the presence of statistically significant differences in the level of social alienation among addicts, for the benefit of the older age groups.

Indicators of social worker roles to improve the quality of life and reduce the feeling of social alienation for drug addicts:

Preventive role: clarifying the disadvantages of drugs and their impact on the quality of addict life (health, psychological, social relations, environment), through seminars and lectures on an ongoing basis to prevent sulertance abuse.

Therapeutic role: by setting up treatment programs for addicts in addiction treatment institutions aimed at integrating them into society to improve their quality of life and reduce their sense of social alienation, as well as developing programs based on spiritual treatment strengthens deistically side to reduce addiction.

A developmental role: through the social worker's interest in preparing social, recreational and cultural programs to positively fill the free time of addicts, which limits their tendency towards drugs and contributes to improving their quality of life and reducing their sense of social alienation.

The role of the mediator: The social worker provides information to the addicts and their families Aleut community institutions that provide services that can be benefited from and facilitate the procedures for obtaining services.

The role of the activist: encourage the addict to continue medical and psychological treatment, as well as pushing the addict's family to provide the necessary support to him, which help to improve the quality of his life as well as reduce the feeling of social alienation.

The role of the behavior changer: through the social worker changing the negative behavior patterns and habits of the addict that led to the addictive behavior with the aim of eliminating this behavior.

The role of the teacher: helping the addict to face his problem or making specific decisions, through lectures - seminars - modeling and teach the addict new behavioral patterns, holding seminars for addicts families to provide methods of dealing with an addict to prevent relapse. 


\section{Research proposals:}

- Effectiveness of life model in enhancing the quality of life for drug addicts.

- Effectiveness of C.B.T in reducing the feeling of social alienation for drug addicts.

\section{The obstacles that the researcher faced:}

- Some addicts refused to cooperate in filling the scale of the study.

- The application took a relatively long time due to the absence of all sample members at the same time inside the hospital. The sample is variable as the duration of stay of the addict is 40 days, including medical treatment and psychosocial rehabilitation.

\section{References}

Abdel Wahab, A. A. (2016). Social Alienation Scale, Cairo, Anglo-Egyptian Library.

Abdel-Samad, H. (2019). Quality of life among a sample of drug addicted youth, Journal of Psychological and Educational Studies, Kasdi Merbah University, Vol. 12, p. 2, pp. 111-120.

Abrahamsson,T,. Berglund,M \& Anders Hakansson,A (2015). Non-Medical Prescription Drug Use (NMPDU) and Poor Quality of Life in the Swedish General Population, The American Journal on Addictions, 24: 271-277 DOI: 10.1111/j.1521-0391.2015.12184.x.

Abu Manjil, M. A. (2012). Social causes of drug abuse, Journal of the College of Education, University of Tripoli, p. 8, pp. 38-55.

Ahmed, A. A. (2017). Alienation, drug abuse and addiction: a sociological study, Arab Center for Education and Development, The Future of Arab Education, Vol. 24, v. 107, pp. 11-80.

Ahmed, B. I. (2013). Quality of Life Scale "The Brief Image" Prepared by (WHO, 1996), Cairo, Anglo-Egyptian Library.

Al Saud, A., Saud.B. (2006).. Addiction, alienation and assertiveness in Saudi and English drug addicts (Order No. U221659). Available from ProQuest Dissertations \& Theses Global. (301726884). Retrieved from https://www.proquest.com/dissertations-theses/addiction-alienationassertiveness-saudi-english/docview/301726884/se-2?accountid=178282

Al-Huwaish, Y. M. (2017). The reasons for the spread of drug abuse among youth, its effects and ways to prevent it, Arab Journal for Security Studies, Naif University for Security Sciences, Vol. 33, p. 70, p.p 251-280.

Al-Saud, L. A., Abu Romi, R. J. (2019). Social alienation and its relationship to drug addiction in the light of some variables: a comparative study between a sample of drug addicts and non-addicts, Journal of Human and Social Sciences Studies, University of Jordan, Vol. 46, P.P 97- 113.

Armstrong, G., Nuken, A., Samson, L. et al. (2013). Quality of life, depression, anxiety and suicidal ideation among men who inject drugs in Delhi, India. BMC Psychiatry 13, 151. https://doi.org/10.1186/1471-244X-13-151

Barker,p (2007) Basic Family Therapy, Britch, Black well Publishing, $5^{\text {th }}$.

Cerne A, Rifel J, Rotar-Pavlic D, Svab I, Selic P, Kersnik J. (2013). Quality of life in patients with depression, panic syndrome, other anxiety syndrome, 
alcoholism and chronic somatic diseases: A longitudinal study in Slovenian primary care patients. Wien Klin Wochenschr. 125:1-7.

Deacon,L\&Macdonald,J.S.(2017). Social Work Theory\&Practice, UK, SAGE.

Hallit, S., Haddad, C., Obeid, S., Kazour, F., Nabout, R., Darwich, M. J. \& Tahan, F. E. (2019). Identification of Factors Affecting the Quality of Life among Patients with Addiction in Lebanon. The Journal of Nervous and Mental Disease, 207(5), 378-383. Doi: 10.1097/NMD.0000000000000982.

Heydarpour, S., Jalali, A., Baghaei, F., \& Salari, N. (2020). Validation and psychometric properties of the drug users' quality of life scale in Iranian population. Substance Abuse Treatment, Prevention \& Policy, 15(1), 1-9. https://doi.org/10.1186/s13011-020-00289-z

Hindi, A. (2017). Quality of life and aging: a comparative field study of a sample of the elderly using the World Health Organization scale, Journal of the College of Arts, Vol. 77, p. 243: 293.

Horman, R.E (2009). Alienation and Student Drug Use, International Journal of the Addictions, 8:2, 325-331, DOI: 10.3109/10826087309057479

Hoseinifar J, Zirak SR, Shaker A, Meamar E, Moharami H, Siedkalan MM (2011). Comparison of quality of life and mental health of addicts and nonaddicts. ProcediaSoc Behav Sci. 30:1930-1934 DOI: 10.1016/j.sbspro.2011.10.375

Jha, D., \& Singh, R. (2020). Analysis of associations between emotions and activities of drug users and their addiction recovery tendencies from social media posts using structural equation modeling. BMC Bioinformatics, 21(18), 1-38. https://doi.org/10.1186/s12859-020-03893-9

Kabqoub, I; Saidi, A. (2015). Psychological alienation and drug abuse among the (schooled) adolescent, a case study, Journal of Psychological and Educational Sciences, Algeria, 1 (1), pg. 2016: 237.

Marcon SR, Rubira EA, Espinosa MM, Barbosa DA (2012). Quality of life and depressive symptoms among caregivers and drug dependent, Rev Lat Am Enfermagem - 20 (1); 167-74.

Matusitz J. (2020). Social Alienation. In: Global Jihad in Muslim and non-Muslim Contexts. Palgrave Macmillan, Cham. https://doi.org/10.1007/978-3-03047044-9 5

Miqdadi, Y. M. (2019). Quality of life and stigma among a sample of drug addicts, Master's thesis, College of Education, Yarmouk University, Jordan.

Muller AE, Skurtveit S, Clausen T (2016) many correlates of poor quality of life among substance users entering treatment are not addiction-specific. Health Qual Life Outcomes. 14:39. DOI: 10.1186/s12955-016-0439-1

Nina, C (2021). The Role of Social Isolation in Opioid Addiction. Social Cognitive and Affective Neuroscience. 10.1093/scan/nsab029

Pienaar, K., Moore, D., Fraser, S., Kokanovic, R., Treloar, C., \& DilkesFrayne, E. (2017). Diffracting addicting binaries: An analysis of personal accounts of alcohol and other drug 'addiction.' Health, 21(5), 519-537. https://08113gjsa-1104-y-https-doiorg.mplbci.ekb.eg/10.1177/1363459316674062

SAATCIOGLU,O., YAPICI,A., \& CAKMAK.D(2008). Quality of life, depression and anxiety in alcohol dependence, Drug and Alcohol Review , 27, 83-90 


\begin{tabular}{|lr||}
\hline Egyptian Journal of Social Work (EJSW) & http://ejsw.journals.ekb.eg \\
ISSN: 2356-9204 & Vol 13, Issue 1, January 2022 \\
\hline \hline
\end{tabular}

Safipour, J., Tessma, M. K., Higginbottom, G. \& Emami, A. (2010). Measuring social alienation in adolescence: Translation and validation of the Jessor and Jessor Social Alienation Scale. Scandinavian Journal of Psychology 51, 517524.

Shakeri J, Ahmadi SM, Maleki F 'Hesami MR, Parsa M, Ahmadzade A, et.,al(2020). Effectiveness of Group Narrative Therapy on Depression, Quality of Life, and Anxiety in People with Amphetamine Addiction: A Randomized Clinical Trial, Iran J Med Sci, Vol 45, No 2.

Stevanovic,D ., Atilola,O., Balhara,Y., Avicenna, M., Kandemir,H., Vostanis,P., Knez.R., \& Petar Petrov.P (2015). The Relationships Between Alcohol/Drug Use and Quality of Life Among Adolescents: An International, Cross-Sectional Study, Journal of Child \& Adolescent Substance Abuse, 24:4, 177-185, DOI: 10.1080/1067828X.2013.773864

Sujan, M.S.H., Tasnim, R., Hossain, S. et al. (2021). Impact of drug abuse on academic performance and physical health: a cross-sectional comparative study among university students in Bangladesh. J Public Health (Berl.). https://doi.org/10.1007/s10389-020-01428-3

Suleiman, E. K.(2015). The role of quality of life in predicting substance dependence and relapse, The National Journal of Abuse and Addiction Studies, The National Center for Social and Criminological Research, Vol. 12, p. 2, p. 141: 146.

Teater, B (2014). Applying social work theories and methods (2 nd edition).maidenhead: Open University press.

United Nations Information Centre, Cairo, 2019. 
